LINGUA, Vol. 14, No. 1, Maret 2017

p ISSN: 1979 9411; e ISSN: 2442 238X

Http://lingua.pusatbahasa.or.id; Email: presslingua@gmail.com

Center of Language and Culture Studies, Surakarta, Indonesia

Silokhah, Imroatus. 2017. Penerapan Metode Role Play pada Matakuliah Public Speaking untuk Mahasiswa Jurusan Pendidikan Bahasa Inggris di IAIN Surakarta.

Lingua, (2017), 14(1): 1 12.

\title{
PENERAPAN METODE ROLE PLAY PADA MATAKULIAH \\ PUBLIC SPEAKING UNTUK MAHASISWA JURUSAN \\ PENDIDIKAN BAHASA INGGRIS DI IAIN SURAKARTA
}

\author{
Imroatus Solikhah \\ Program Studi Pendidikan Bahasa Inggris \\ IAIN Surakarta \\ Jl. Pendowo, Pucangan Kartasura \\ Email: iimqueenoslo@gmail.com \\ Diterima tanggal: 10 November 2016 \\ Diterima untuk diterbitkan tanggal: 10 Desember 2016
}

\begin{abstract}
This study explores instructional process, individual performance, and attainments on public speaking. Classroom action research design with three cycles and 12 meetings was used. Conducted in IAIN Surakarta on March to June 2016, it assigned 26 students of semester IV-B as subject. Check list, interview, and field notes were used as the instruments. The analyses foused on classroom participation, individual performance, and scores on formative test. This study revealed that: (1) In Cycle I, motivation, partipation and performance were low, mean scores of classrom participation was $64.10 \%$ (fair), individual performance 58.46 (low) and formative test 65.12 (fair); (2) In Cycle II, learning participation, encouragement and motivation increased. Average scores on classroom participation was $81,41 \%$ (good), individual performance $71,92 \%$ (fair) and formative test 74,81 (fair). (3) Cycle III achieved higher gains in participation, motivation, enrouragement, and test. Average scores on classroom participation, individual performance and formative test attainments were 83,98\% (good), 81,54\% (good), and 80,27 (good). The use of 14 aspects of public speaking as template and appeals of persuation from Aristoteles: ethos, pathos and logos was crucial.
\end{abstract}

Keywords: role play, public speaking, EFL, IAIN Surakarta.

Penggunaan bahasa melibatkan tindak berbahasa yang berkaitan dengan pengaruh, bentuk dan ragam bahasa. Unsur-unsur itu meliputi: siapa, tentang apa, dengan jalur apa (tulisan, lisan, dsb) dan ragam bahasa yang mana. Dell Hymes (1972) dalam Nababan (1991:7) menjelaskan unsur bahasa tersebut sebagai components of speech yang merupakan unsur-unsur yang menyebabkan penggunaan suatu bahasa 
LINGUA, Vol. 14, No. 1, Maret 2017

p ISSN: 1979 9411; e ISSN: 2442 238X

Http://lingua.pusatbahasa.or.id; Email: presslingua@gmail.com

Center of Language and Culture Studies, Surakarta, Indonesia

Silokhah, Imroatus. 2017. Penerapan Metode Role Play pada Matakuliah Public Speaking untuk Mahasiswa Jurusan Pendidikan Bahasa Inggris di IAIN Surakarta.

Lingua, (2017), 14(1): 1 12.

terjadi dan memiliki makna. Untuk menunjukkan bagaimana unsur-unsur bahasa saling terkait dalam perilaku berbahasa, Hymes membuat akronim SPEAKING sebagai berikut:

$\mathbf{S}$ (setting and scene)

$\mathbf{P}$ (participants)

$\mathbf{E}$ (ends, purposes and goals)

A (act sequences)

$\mathbf{K}$ (key, tone or spirit of act)

I (instrumentalities, jalur, channel)

$\mathbf{N}$ (norms of interactions and interpretations)

$\mathbf{G}$ (genres, bentuk dan ragam bahasa)

Unsur-unsur bahasa tersebut jika dikaji secara cermat memiliki peranan penting dalam proses pembelajaran speaking (berbicara). Unsur-unsur bahasa merupakan tindak berbahasa yang terjadi dalam setiap interaksi dan pembelajaran speaking terjadi mengikuti dan melibatkan unsur-unsur berbahasa tersebut. Menurut Hymes (1972) peristiwa bahasa melibatkan: latar, partisipan, tujuan, rangkaian urutan, nada, saluran, norma berbicara, dan ragam bahasa. Unsur-unsur berbahasa tersebut memiliki peranan penting dalam pembelajaran speaking bagi mahasiswa.

Penguasaan speaking bagi mahasiswa jurusan Pendidikan Bahasa Inggris merupakan kompetensi wajib. Ada dua alasan yang menguatkan peranan penguasaan speaking bagi mahasiswa dalam konteks ini.

Pertama, speaking merupakan kompetensi yang harus dikuasai mahasiswa untuk memahami dan memperoleh informasi secara verbal. Selain itu, speaking juga merupakan media bagaimana memahami orang lain melalui interaksi lisan dan menjadi indikator penutur menguasai bahasa yang digunakan. Nunan (1999) menjelaskan:

" ... the ability to function in another language is generally characterized in terms of being able to speak that language. People measure the mastery of a language by seeing whether one can speak the language or not."

Kedua, belajar bahasa harus mencapai literasi berbahasa secara baik. Dalam konteks ini, pembelajaran bahasa harus mendorong pembelajar untuk mencapai empat literasi berbahasa sebagai kompetensi utuh yang menunjukkan pembelajar menguasai bahasa secara konsep dan praktik. Keempat literasi berbahasa tersebut ialah: (1) literasi performative, kemampuan membaca, menulis, dan berbicara; (2) literasi functional, kemampuan menggunakan bahasa untuk memenuhi kebutuhan hidup sehari-hari seperti 
LINGUA, Vol. 14, No. 1, Maret 2017

p ISSN: 1979 9411; e ISSN: 2442 238X

Http://lingua.pusatbahasa.or.id; Email: presslingua@gmail.com

Center of Language and Culture Studies, Surakarta, Indonesia

Silokhah, Imroatus. 2017. Penerapan Metode Role Play pada Matakuliah Public Speaking untuk Mahasiswa Jurusan Pendidikan Bahasa Inggris di IAIN Surakarta.

Lingua, (2017), 14(1): 1 12.

membaca surat kabar, membaca manual; (3) literasi informational, kemampuan mengunduh pengetahuan menggunakan bahasa Inggris; dan (4) literasi epistemic, kemampuan mentransformasi pengetahuan menggunakan bahasa Inggris (Solikhah, 2014:4; Depdiknas, 2003:5).

Penguasaan bahasa sebagaimana dikemukakan di atas, harus menjadi kompetensi dasar yang dicapai mahasiswa jurusan Pendidikan Bahasa Inggris secara umum. Materi tersebut diajarkan pada semester IV dengan nama matakuliah Speaking IV dan learning outcomes Public speaking serta kompetensi minimal mahasiswa penguasaan pidato dan presentasi. Mata kuliah speaking untuk mahasiswa semester 4 pada jurusan Pendidikan Bahasa Inggris ini ialah Public Speaking. Isi materi mata kuliah ini bertujuan untuk membekali mahasiswa berbicara secara aktif dan mampu berkomunikasi dengan orang dalam konteks nyata di depan umum atau di depan orang banyak, sebagaimana fungsi bahasa untuk berkomunikasi (Brown, 2000:5) melalui penerapan metode yang sesuai.

Penelitian ini dilakukan untuk mengkaji pembelajaran public speaking mahasiswa jurusan Pendidikan Bahasa Inggris di Fakultas Ilmu Tarbiyah dan Keguruan (FITK) di IAIN Surakarta. Fokus penelitian ialah pembelajaran speaking IV yang kompetensinya ditetapkan untuk penguasaan public speaking berupa presentasi dan pidato.

Hasil observasi di lapangan menunjukkan mahasiswa public speaking diajarkan di semester 4 untuk jurusan bahasa Inggris FITK, IAIN Surakarta berjumlah 10 kelas. Mula-mula dosen menggunakan task-based approach dalam pembelajaran speaking di kelas lebih rendah. Setelah berdiskusi dengan peneliti, dosen disarankan agar menerapkan teknik role play untuk mengajar public speaking. Mata kuliah public speaking di semester 4 diampu oleh 3 dosen (2 laki-laki dan 1 perempuan) untuk mengajar 10 kelas.

Berdasarkan hasil diskusi, diketahui bahwa dosen cenderung penggunaan metode role play untuk kelas public speaking. Hasil interview dengan dosen pengampu menunjukkan bahwa role play dianggap bisa meningkatkan motivasi dan antusisme dalam praktik berbicara mahasiswa menjadi lebih baik. Adapun hasil interview dengan mahasiswa menyebutkan bahwa metode ini membantu mahasiswa untuk berbicara dengan lebih baik karena bisa mengurangi rasa cemas disaat berbicara secara kelompok bahkan mampu menimbulkan rasa percaya diri dengan lebih baik saat tampil di depan kelas.

Dalam pembelajaran di kelas, ternyata pembelajaran public speaking belum terarah pada kompetensi public speaking, melainkan memiliki kemiripan dengan speaking secara umum. Pertama, penekanan pembelajaran mengacu pada topik bukan task. Hal ini bertentangan dengan pendapat Folse (2009) yang menegaskan bahwa topik 
LINGUA, Vol. 14, No. 1, Maret 2017

p ISSN: 1979 9411; e ISSN: 2442 238X

Http://lingua.pusatbahasa.or.id; Email: presslingua@gmail.com

Center of Language and Culture Studies, Surakarta, Indonesia

Silokhah, Imroatus. 2017. Penerapan Metode Role Play pada Matakuliah Public Speaking untuk Mahasiswa Jurusan Pendidikan Bahasa Inggris di IAIN Surakarta.

Lingua, (2017), 14(1): 1 12.

memang diperlukan dalam pembelajaran speaking tetapi topik tersebut harus dipilih yang bisa memberi aktifitas untuk berbicara (task). Kedua, rubrik penilaian yang digunakan ialah rubrik untuk speaking, bukan public speaking. Rubrik penilaian speaking tersebut tampak dari aspek yang dinilai, yaitu: fluency, pronunciation, grammar, vocabullary, dan contents. Selain itu, kosa kata dan grammar juga memperoleh porsi dan proporsi yang penting dalam pembelajaran speaking. Grammar yang harus dikuasai ialah basic grammar dan kalimat sederhana, kalimat majemuk, kalimat yang memiliki beberapa klausa yang digunakan dalam teks akademik seperti buku teks, jurnal dan paper (Wilson, 2009:24-25; Burke, 2013:1-2 di Solikhah, 2014:5). Model ini tidak terlalu keliru, tetapi orientasi pembelajaran yang berfungsi untuk menentukan kompetensi standar dan learning outcome mata kuliah menjadi kurang tepat.

Tentu saja orientasi ini bisa menghasilkan ancaman bagi pembelajaran public speaking. Berbagai kajian literatur, misalnya Yamashito dan Johnson (2013) yang mendesain Course Outline untuk public speaking, Zhengdon (2012) yang meneliti pembelajaran public speaking di Hong Kong dan Oradee (2012) yang meneliti pembelajaran public speaking di Thailand menunjukkan bahwa pembelajaran public speaking harus mengacu pada oral production dan aspek berbicara di depan publik.

Berbicara di depan publik telah mendapat pola yang mapan sejak Aristoteles 4SM mengemukakan penggunaan appeals persuasion yaitu: ethos (kredibilitas pembicara), pathos (keahlian memancing emosi pendengar), dan logos (keruntutan logika dalam menyampaikan argumentasi). Dalam teknik modern, teori Aristoteles tersebut telah dikembangkan menjadi 14 aspek kunci untuk membuat pidato sukses. Ke14 kunci tesebut ialah: (1) control voice, mencakup: projection, pace, intonation, diction, (2) body language, meliputi: posture, eye concacat, gesture, (3) order of oral presentation, mancakup introduction, the body, conclusion, dan (4) effectiveness, meliputi: topic, language use, vocabulary, purpose. Dalam pembelajaran public speaking dan pelatihan public speaking secara profesional di perusahaan, 14 aspek tersebut ialah fokus pelatihan yang dikerjakan secara intensif. Oleh sebab itu pembelajaran public speaking di kelas harus diubah orientasinya.

Atas dasar kajian awal tersebut, peneliti merumuskan bahwa pembelajaran public speaking akan lebih bermakna jika diajarkan menggunakan teknik role play. Orientasi public speaking yang sesuai bukanlah mengacu pada penguasaan speaking, tetapi presentasi dan pidato. Adapun teknik pidato dan materi pokok yang harus disajikan ialah 14 aspek pidato efektif dan penyajian public speaking secara efektif merujuk pada teori persuasi dari Aristoteles. Tentu saja aspek penguasaan bahasa Inggris tetap harus diperhatikan. Materi public speaking juga harus mengacu pada mendorong mahasiswa menguasai keterampilan berbicara yang dilakukan terintegrasi 
LINGUA, Vol. 14, No. 1, Maret 2017

p ISSN: 1979 9411; e ISSN: 2442 238X

Http://lingua.pusatbahasa.or.id; Email: presslingua@gmail.com

Center of Language and Culture Studies, Surakarta, Indonesia

Silokhah, Imroatus. 2017. Penerapan Metode Role Play pada Matakuliah Public Speaking untuk Mahasiswa Jurusan Pendidikan Bahasa Inggris di IAIN Surakarta.

Lingua, (2017), 14(1): 1 12.

dengan praktik berbicara. Berdasarkan latar belakang di atas, pertanyaan penelitian ini dirumuskan sebagai berikut:

1) Bagaimana proses implementasi pembelajaran menggunakan teknik role play di kelas public speaking untuk mahasiswa jurusan Pendidikan Bahasa Inggris?

2) Bagaimana hasil pembelajaran public speaking menggunakan teknik role play dilihat dari aktifitas pembelajaran dan tampilan mahasiswa dalam belajar public speaking di kelas?

3) Bagaimana capaian mahasiswa dalam tes formatif public speaking setelah diajar menggunakan teknik role play?

\section{METODE}

Penelitian ini menggunakan rancangan penelitian tindakan kelas (Kemmis dan Taggart, 2004) dengan tiga siklus yang dilaksanakan dalam 12 tatap muka. Penelitian dilaksanakan di Jurusan Bahasa Inggris IAIN Surakarta pada Maret sampai Juni 2016, dan menggunakan 26 mahasiswa semester IV-B sebagai subjek penelitian. Instrumen penelitian terdiri dari cek list untuk mengamati aktifitas pembelajaran dan tampilan individu dalam proses belajar, interview dan catatan lapangan. Kinerja public speaking, diukur menggunakan rubrik 14 aspek public speaking. Data dianalisis untuk mengetahui aktifitas pembelajaran, tampilan individu dan skor tes formatif.

\section{HASIL}

\section{Proses Pembelajaran}

Proses pembelajaran dirumuskan berdasarkan rancangan pembelajaran public speaking menggunakan teknik role playing yang meliputi: di awal pembelajaran mahasiswa diarahkan untuk menguasai aspek akademis, penyajian presentasi dalam public speaking dan penilaian melalui rubrik public speaking dan rubrik penilaian speaking secara umum. Rubrik tersebut dipraktikkan untuk menilai teman sejawat dan dibahas untuk memberi komentar tampilan setiap mahasiswa. Selanjutnya, mahasiswa dilatih melalui praktik pidato informal dan pidato formal dan setiap tampilan pidato dinilai menggunakan rubrik aspek pidato kemudian dibahas untuk perbaikan tampilan berikutnya. Tampilan mahasiswa dilaksanakan selama tiga siklus; pertama untuk melatih pidato informal, kedua untuk pidato formal, dan ketiga untuk tes formatif pidato formal dan pidato informal.

Hasil pengamatan proses pembelajaran public speaking menggunakan teknik role playing untuk pembelajaran pidato atau presentasi topik formal dan topik informal ialah:

1) Siklus I menunjukkan pembelajar belum memiliki kesadaran untuk berpartisipasi dalam kelompok, masih bekerja sendiri, belum menunjukkan motivasi bekerjasama, 
LINGUA, Vol. 14, No. 1, Maret 2017

p ISSN: 1979 9411; e ISSN: 2442 238X

Http://lingua.pusatbahasa.or.id; Email: presslingua@gmail.com

Center of Language and Culture Studies, Surakarta, Indonesia

Silokhah, Imroatus. 2017. Penerapan Metode Role Play pada Matakuliah Public Speaking untuk Mahasiswa Jurusan Pendidikan Bahasa Inggris di IAIN Surakarta.

Lingua, (2017), 14(1): 1 12.

masih suka mengganggu kinerja kelompok lain dan belum fokus pada upaya menguasai kemampuan public speaking. Dari segi penguasaan materi mahasiswa belum terdorong untuk menguasai strategi berpidato atau presentasi lisan di depan publik dan belum menyadari bahwa penguasaan skill berbicara dibutuhkan.

2) Pada siklus II, setelah mahasiswa diberi penjelasan mengenai fungsi public speaking, 14 aspek yang dinilai dalam public speaking dan diajak mempraktikkan penilaian teman lainnya yang sedang tampil pidato, mahasiswa mulai menyadari fungsi public speaking dan pengembangan strategi belajar public speaking. Pembelajaran pada siklus II berjalan cukup kondusif ditandai dengan partisipasi mahasiswa meningkat, keberanian bertanya dan mengerjakan task meningkat dan mahasiswa menunjukkan upaya serius menguasai strategi belajar public speaking dan memperbaikai kesalahan tampilan dan penguasaan skill berbicara.

3) Pada siklus III, proses belajar mengajar ditandai dengan upaya mahasiswa mempersiapkan secara mandiri semua proses pembelajaran yang diperlukan. Karena siklus III dirancang dilaksanakan dalam bentuk tes formatif, mahasiswa nampak menunjukkan motivasi yang tinggi, partisipasi yang tinggi, kegairahan dan belajar mandiri. Kemandirian ini tampak dari bagaimana mahasiswa menyiapkan topik pidato, menyiapkan slide untuk presentasi, berlatih menggunakan bahasa Inggris mengikuti rubrik penilaian dan upaya bekerjasama dengan teman satu grup atau teman di luar grup.

\section{Hasil Pengamatan Aktifitas Pembelajaran dan Tampilan Individu}

Hasil pengamatan aktifitas pembelajaran dilakukan untuk melihat tingkat aktifitas pembelajaran dan tampilan individu dalam berlatih pidato atau presentasi dalam kelompok.

1) Pada siklus I, hasil pengamatan aktifitas pembelajaran dari 26 mahasiswa ialah: (1) baik 6 (23.08\%), (2) cukup $12(46,14 \%)$, dan (3) kurang 8 (30,08\%). Tidak ada mahasiswa yang mencapai hasil sangat baik. Rerata persentase aktifitas pembelajaran siklus I ialah 64,10\%. Mahasiswa yang sudah mencapai KKM = 75 ialah $6(23,08 \%)$.

Tampilan individu pada siklus I ialah rerata $58.46 \%$ dan distribusi persentase menurut 10 indikator ialah: (1) produktifitas 12 (46,15\%), (2) tujuan 19 (73,08\%), (3) interaktif $11(42,30 \%)$, (4) menantang $14(53,85 \%)$, (5) percaya diri 14 (53,85\%), (6) otentik 15 (57,69\%), (7) reproduksi 19 (73,08\%), (8) komunikasi 14 $(53,85 \%)$, (9) pengembangan wacana $20(76,92 \%)$, dan (10) kelancaran dan kefasihan $14(53,85 \%)$.

2). Pada siklus II, pengamatan aktifitas pembelajaran memeiliki rerata $81.41 \%$ dan 
LINGUA, Vol. 14, No. 1, Maret 2017

p ISSN: 1979 9411; e ISSN: 2442 238X

Http://lingua.pusatbahasa.or.id; Email: presslingua@gmail.com

Center of Language and Culture Studies, Surakarta, Indonesia

Silokhah, Imroatus. 2017. Penerapan Metode Role Play pada Matakuliah Public Speaking untuk Mahasiswa Jurusan Pendidikan Bahasa Inggris di IAIN Surakarta.

Lingua, (2017), 14(1): 1 12.

distribusi capaian berikut: (1) sangat baik 2 (7.69\%), (2) baik $11(42,31 \%)$, (3) cukup $6(23,07 \%)$, dan (4) kurang 7 (26,92\%). Rerata aktifitas pembelajaran siklus II ialah $81.41 \%$ dan jumlah mahasiswa yang mencapai $\mathrm{KKM}=75$ ialah $13(50 \%)$.

Pengamatan tampilan individu siklus II menunjukkan rerata $71,69 \%$ dan distribusi capaian berikut: (1) produktifitas $18(69,23 \%)$, (2) tujuan $15(57,69 \%)$, (3) interaktif $21(80,77 \%)$, (4) menantang $20(76,92 \%)$, (5) percaya diri $19(73,08 \%)$, (6) otentik $19(73,08 \%)$, (7) reproduksi $21(80,76 \%)$, (8) komunikasi $19(73,08 \%)$, (9) pengembangan wacana $20(76,92 \%)$, dan (10) kelancaran dan kefasihan 15 $(57,69 \%)$.

3) Pada siklus III, hasil pengamatan aktifitas pembelajaran menunjukkan rerata $83.98 \%$ dan distribusi capaian berikut: (1) sangat baik, 5 (19.33\%), (2) baik, 15 (57,69\%), (3) cukup, 3 (11,54\%), dan (4) kurang, 3 (11,54\%). Distribusi ini menunjukkan bahwa terdapat $20(76,92 \%)$ mahasiswa yang memiliki capaian aktifitas di atas $\mathrm{KKM}=75 \%$. Ada 6 mahasiswa yang belum mencapai KKM.

Pengamatan tampilan individu pada siklus III menunjukkan rerata $81,54 \%$ dan distribusi capaian berikut: (1) produktifitas 20 (76,92\%), (2) tujuan $23(88,46 \%)$, (3) interaktif $21(80,77 \%)$, (4) menantang $22(84,62 \%)$, (5) percaya diri $21(80,77 \%)$, (6) otentik $22(84,62 \%)$, (7) reproduksi $24(92,30 \%)$, (8) komunikasi 19 (73,08\%), (9) pengembangan wacana 20 (76,92\%), dan (10) kelancaran dan kefasihan 20 (76,92\%). Rerata $81,54 \%$.

\section{Capaian Skor Tes Formatif Public Speaking}

Capaian skor tes diperoleh dari tes formatif public speaking di akhir siklus I dan siklus II dan final tes pada siklus III. Hasil tes formatif menunjukkan: (1) Siklus I: rerata 65.12 dan distribusi skor: (1) $\mathrm{B}=11(42,31 \%)$, (2) $\mathrm{C}=6(23,08 \%)$, dan (3) $\mathrm{D}=9$ (34,61\%); (2) Siklus II: rerata 71, $92 \%$ dan distribusi skor: (1) $\mathrm{A}=3(11,54 \%)$, (2) $\mathrm{B}=$ $10(38,46 \%)$, (3) $\mathrm{C}=23,08 \%$, (4) $\mathrm{D}=6$ (23,08\%, dan (5) $\mathrm{E}=26,92 \%$. Terdapat 13 (50\% mahasiswa sudah mencapai KKM; (3) Siklus III: rerata 80,27 dan distribusi skor: (1) A, 6 (23,08\%), (2) B, 15 (57,69\%), (3) C, 3 (11,54\%), (4) D, 2 (7,69\%). Terdapat 21 $(80,76 \%)$ mahasiswa mencapai nilai di atas $\mathrm{KKM}=75$.

\section{BAHASAN}

Pembelajaran public speaking menggunakan teknik role playing dalam penelitisan ini berhasil dilaksanakan setelah dilakukan tindakan selama 12 pertemuan yang dibagi ke dalam tiga siklus. Keberhasilan ini disebabkan aktifitas pembelajaran mahasiswa menjadi menarik dan meningkatkan motivasi serta kreatifitas mahasiswa 
LINGUA, Vol. 14, No. 1, Maret 2017

p ISSN: 1979 9411; e ISSN: 2442 238X

Http://lingua.pusatbahasa.or.id; Email: presslingua@gmail.com

Center of Language and Culture Studies, Surakarta, Indonesia

Silokhah, Imroatus. 2017. Penerapan Metode Role Play pada Matakuliah Public Speaking untuk Mahasiswa Jurusan Pendidikan Bahasa Inggris di IAIN Surakarta.

Lingua, (2017), 14(1): 1 12.

setelah mahasiswa diberi peran dalam proses pembelajaran yang sesuai untuk mendorong mahasiswa berbicara.

Keberhasilan menerapkan role playing ini dievaluasi melalui tiga kriteria: aktifitas pembelajaran, skor tes formatif public speaking, dan tampilan dalam proses pembelajaran public speaking di kelas. Ketiga kriteria ini dicapai secara bertahap dari siklus I, siklus II dan siklus III. Capaian pada siklus I menunjukkan hasil yang belum maksimal. Capaian pada siklus II menunjukkan hasil yang meningkat tetapi belum semua kriteria terpenuhi. Tindakan yang diberikan pada siklus I sebanyak tiga tatap muka dan pada siklus II juga sebanyak tiga tatap muka, masih belum bisa meningkatkan seluruh kriteria pembelajaran public speaking. Kesalahan tampilan, motivasi naik turun, dan kegairahan belajar yang tidak stabil menyebabkan hasil belajar belum maksimal. Capaian maksimal baru tercapai setelah tindakan dalam siklus III selesai dilaksanakan. Keberhasilan ini mengkonfirmasi bahwa teknik role playing dalam pembelajaran public speaking berhasil mendorong motivasi, kreatifitas, kegairahan belajar, tujuan, dan menantang mahasiswa untuk mencapai learning authonomy (pembelajaran mandiri).

Capaian nilai dari siklus I sampai siklus III menunjukkan peningkatan secara konsisten pada tiga aspek: aktifitas pembelajaran, tampilan public speaking dan tes formatif. Rerata capaian aktifitas pembelajaran berturut-turut ialah: 64,10\%, 81,41\%, dan $83,98 \%$. Rerata capaian mahasiswa dalam tampilan berpidato secara individu dalam siklus I sampai siklus III berturut-turut ialah: 58,46\%, 71,92\%, dan 81,54\%. Terjadi peningkatan yang signifikan dilihat dari capaian persentase tampilan berlatih pidato. Capaian ini terjadi karena mahasiswa diajak melakukan self-rating terhadap tampilan grup lainnya sebagai penilai sejawat sehingga mahasiswa akan tahu dan menyadari kelemahan apa yang harus diperbaiki jika nanti mahasiswa tersebut mendapat giliran tampil berpidato. Selain itu, mengkaji 14 aspek kunci pidato dan mempraktikkannya secara mandiri di rumah berhasil meningkatkan kemampuan mahasiswa. Hasil ini didukung oleh temuan Yamashiro \& Johnson (2013) yang meneliti kemampuan public speaking mahasiswa kelas internasional di Tokyo. Temuan ini memastikan bahwa diskusi dan penyadaran mahasiswa mengenai rubrik penilaian pidato dan kajian terhadap 14 kunci sukses pidato akan menyadarkan mahasiswa untuk meningkatkan tampilan pidato, meningkatkan penguasaan bahasa Inggris, dan mengefektifkan proses penyajian dan organisasi dalam pidato.

Ada tiga hal terkait pembelajaran public speaking yang bisa diklarifikasi. Pertama, dalil argumentasi Aristoteles tentang penggunaan persuasive appeals, yaitu ethos (kredibilitas pembicara dalam menyampaikan topik), pathos (kualitas kemampuan pembicara memancing emosi pendengar), dan logos (argumen yang logis) meyakinkan dan relevan dengan teknik pidato modern. Dalil ini dikofirmasi oleh kajian contrastive 
LINGUA, Vol. 14, No. 1, Maret 2017

p ISSN: 1979 9411; e ISSN: 2442 238X

Http://lingua.pusatbahasa.or.id; Email: presslingua@gmail.com

Center of Language and Culture Studies, Surakarta, Indonesia

Silokhah, Imroatus. 2017. Penerapan Metode Role Play pada Matakuliah Public Speaking untuk Mahasiswa Jurusan Pendidikan Bahasa Inggris di IAIN Surakarta.

Lingua, (2017), 14(1): 1 12.

rhetoric dari Connor (2003) dan Budiharso (2014). Hakikatnya dalam berbicara di depan umum, faktor ketersediaan data dan fakta lapangan yang diolah menggunakan teknik melibatkan emosi pendengar lebih efektif dampaknya dalam mempengaruhi opini publik.

Kedua, dalam teknik pidato modern, terdapat 14 faktor yang dijadikan ukuran agar pidato efektif. Faktor tersebut dikatagorikan ke dalam empat hal: voice control, body language, order of presentation, dan effectiveness, sebagai strategi berpidato. Dari emat strategi tersebut, faktor order of presentation (urutan penyajian) dan efektifitas bahasa ialah yang utama yang harus dikuasai pembelajar. Urutan penyajian menunjukkan tahapan pidato ke dalam pendahuluan, isi dan penutup. Adapun efektifitas terkait dengan: topik, penggunaan bahasa, pemilihan kosa kata dan tujuan pidato. Hasil penelitian ini mengkonfirmasi pendapat Richards (2008) dan Harms \& Myers (2013). Pembelajaran speaking yang efektif harus memperhatikan strategi penyampaian dan presentasi atau urutan penyajian lisan secara efektif.

Ketiga, dari segi penguasaan bahasa Inggris, aspek voice of control relevan dengan temuan ini. Voice of control meliputi: pengaturan volume suara, pengaturan kecepatan berbicara, intonasi yang benar dan pemilihan kata yang tepat. Temuan ini dikonfirmasi oleh Yamashiro \& Johnson (2013), Zhengdon Gan (2012), dan Oradee Thanyalak (2012). Ketiga penelitian ini menjelaskan bahwa pembelajaran public speaking akan meningkatkan kemampuan teknis berbahasa Inggris terutama aspek pronunciation, intonation, fluency dan accuracy. Pronunciation dan intonation menekankan pada keharusan pembelajar menguasai pengucapan dan penggunaan nada yang baik dan benar. Penyampaian ide yang tidak didasarai pada pengucapan dan ujaran yang benar akan menganggu makna yang sebenarnya. Adapun pengaturan suara dan kecepatan memproduksi kata dalam satu waktu menunjukkan fluency dan accuracy. Fluency terkait dengan kelancaran dan accuracy terkait dengan kesalahan gramatika dan kesalahan pengucapan yang harus dihindari ketika pembicara menyampaikan pesan dalam bentuk pidato atau bercerita.

Terkait dengan penilaian speaking skills, aspek kebahasaan ialah yang pertama harus dikuasai. Aspek kebahasaan itu meliputi: pronunciation, fluency, vocabulary, dan grammar. Vocabuary dan grammar disebut juga dengan language use atau accuracy. Temuan ini mengkonfirmasi penggunaan rubrik penilaian speaking yang dikemukakan Folse (2009). Dari aspek keterkaitan berbicara dengan rubrik penilaian speaking dari Thornburry (2005) dan Cambridge University (2013) memiliki kesesuaian yang tinggi. Thornburry (2005) menekankan pada: grammar and vocabulary, discourse management, dan interactive communication. Cambridge University membagi fokus penilaian speaking menjadi dua model. Pertama, fokus penilaian diarahkan pada: grammar, vocabulary, fluency, listening, dan voice and non-verbal communication. 
LINGUA, Vol. 14, No. 1, Maret 2017

p ISSN: 1979 9411; e ISSN: 2442 238X

Http://lingua.pusatbahasa.or.id; Email: presslingua@gmail.com

Center of Language and Culture Studies, Surakarta, Indonesia

Silokhah, Imroatus. 2017. Penerapan Metode Role Play pada Matakuliah Public Speaking untuk Mahasiswa Jurusan Pendidikan Bahasa Inggris di IAIN Surakarta.

Lingua, (2017), 14(1): 1 12.

Kedua, penilaian diarahkan pada: grammar and vocabulary, discourse management, pronunciation dan interactive communication. Sejalan dengan pendekatan discourse competence dan pendekatan literasi, rubrik yang dikemukakan oleh Cambridge University memiliki kecenderungan lebih tinggi untuk digunakan secara massal untuk berbagai tujuan tes speaking.

Untuk penilaian public speaking, rubrik yang dikembangkan Cambridge University juga memiliki kecocokan dengan 14 aspek penilaian dalam public speaking. Ke-14 aspek itu ialah: (1) voice control, mencakup: projection, pace, intonation, diction, (2) body language, mencakup: posture, eye contact, gesture, (3) order of oral presentation, mencakup: introduction, the body, closing, dan (4) effectiveness, mencakup: topic, language use, vocabuary, purpose. Penggunaan rubrik ini sejalan dengan temuan Yamashiro \& Johnson (2013) yang menegaskan bahwa 14 aspek penilaian dalam public speaking yang diajarkan kepada mahasiswa dan mahasiswa diajak untuk melakukan penilaian mandiri menggunakan rubrik tersebut terbukti meningkatkan penguasaan mahasiswa dalam public speaking. Capaian diperoleh karena mahasiswa menyadari apa yang dinilai dalam public speaking dan bagaimana strategi mempersiapkan public speaking secara materi, teknik penyampaian ide dan penampilan dalam pidato.

\section{SIMPULAN}

Pembelajaran public speaking menggunakan teknik role playing berhasil. Tiga kriteria keberhasilan ialah: aktifitas pembelajaran, tampilan individu, dan tes formatif public speaking. Capaian nilai dari siklus I sampai siklus III menunjukkan peningkatan secara konsisten pada tiga aspek. Rerata aktifitas pembelajaran ketiga siklus ialah: $64,10 \%, 81,41 \%$, dan $83,98 \%$. Rerata tampilan individu dalam siklus I sampai siklus III ialah: 58,46\%, 71,92\%, dan 81,54\%. Capaian terjadi karena mahasiswa diajak melakukan self-rating mengunakan 14 aspek kunci pidato dan praktik mandiri. Keberhasilan juga didukung tiga hal. Pertama, pemahaman argumentasi Aristoteles persuasive appeals, yaitu ethos, pathos dan logos. Kedua, pemahaman teknik pidato 14 faktor, voice control, body language, order of presentation, dan effectiveness, terutama faktor order of presentation (urutan penyajian) dan efektifitas bahasa ialah yang utama yang harus dikuasai pembelajar; urutan penyajian: pendahuluan, isi dan penutup. Ketiga, penguasaan bahasa Inggris, aspek penilaian pidato voice of control, yaitu pengaturan volume suara, pengaturan kecepatan berbicara, intonasi yang benar dan pemilihan kata yang tepat. 
LINGUA, Vol. 14, No. 1, Maret 2017

p ISSN: 1979 9411; e ISSN: 2442 238X

Http://lingua.pusatbahasa.or.id; Email:presslingua@gmail.com

Center of Language and Culture Studies, Surakarta, Indonesia

Silokhah, Imroatus. 2017. Penerapan Metode Role Play pada Matakuliah Public Speaking untuk Mahasiswa Jurusan Pendidikan Bahasa Inggris di IAIN Surakarta.

Lingua, (2017), 14(1): 1 12.

\section{DAFTAR PUSTAKA}

Armstrong, Davis G, and Savage, Tom V. 1983. Secondary Education Introduction. New York: Macmillan Publishing Co., Inc

Bordens, Kenneth S. and Bruce B. Abbott. 2011. Research Design and Methods: A Process Approach. New York: McGraw-Hill Companies Inc.

Brown , H. Douglas. 2001. Teaching by Principles: An Interactive Approach to Language Pedagogy. New York: Wesley Longman.

Brown, G and Yule, George. 1983. Teaching the Spoken Language. Cambridge: Cambridge University Press

Brown, H. Douglas. 2004. Language Assesment: Principles and Classroom Practices. White Plains, NY: Longman.

Byrne, Donn. 1986. Teaching Oral English. Harlow, England: Longman Group.

Budiharso, Teguh. 2014. Contrastive Rhetoric of Oral and Written Academic Text Analysis. Paper, Samarinda: Mulawarman University.

Burn, Anne \& Joyce, Helen. 1999. Focus on Speaking. Sydney: Macquarie University Press.

Chaudron, C. 1988. Second Language Classroom: Research on Teaching and Learning. New York: Cambridge University Press.

Fauziati, Endang. 2009. Introduction to Method and Approaches in Second a Foreign Language Teaching. Surakarta: Muhammadiyah University Press.

Fraenkel, Jack R. \& Wallen. 2000. How to Design Research in Education (the fourth edition). Boston: McGraw-Hill, Inc.

Folse. Keith S. 2006. The Art of Teaching Speaking. Michigan: University of Michigan Press

Ford-Brown, Lisa A. 2012. Guide to Public Speaking. New York: Pearson Education.

Gan, Zhengdon. 2013. Undestanding L2 Speaking Problems: Implication for ESL Curriculum Development in a Teacher Training Institution in Hong Kong. Australian Journal of Teacher Education, 37(1): 43-59.

Hamilton, Cheryl. 2012. Essentials of Public Speaking. Boston MA: Wadsworth Cengage Learning press.

Lucas, E. Stephen. 2009. The Art of Public Speaking. New York: McGraw Hill Education.

Meleong, Lexy J. 2007. Metode Penelitian Kualitatif. Bandung: PT Remaja Rosdakarya.

Nababan, PWJ. 1991. Sosiolinguistik Suatu Pengantar. Jakarta: PT Gramedia Pustaka Uyama.

Nunan, David. 1999. Language Teaching Methodology. Cambridge: Pearson Education. 
LINGUA, Vol. 14, No. 1, Maret 2017

p ISSN: 1979 9411; e ISSN: 2442 238X

Http://lingua.pusatbahasa.or.id; Email: presslingua@gmail.com

Center of Language and Culture Studies, Surakarta, Indonesia

Silokhah, Imroatus. 2017. Penerapan Metode Role Play pada Matakuliah Public Speaking untuk Mahasiswa Jurusan Pendidikan Bahasa Inggris di IAIN Surakarta.

Lingua, (2017), 14(1): 1 12.

Oradee, Thanyalak. 2012. Developing Oral English Skills Using Three Communication Activities (Discussion, Problem-Solving, and Role Playing). International Journal of Social Science and Humanity, 1(6):533-535. DOI: 10.7763/IJSSH.2012.V2.164.

Oral Communication Program the Center for Teaching and Learning. 2016. An Overview of Effective Speaking. Available at Http://speakinghelp.stanford.edu. Retrieved on 12 July 2016.

Richards, C. Jack. 2008. Teaching Listening and Speaking: from Theory to Practice. Cambridge: Cambridge University Press.

Solikhah, dkk. 2015. Pengembangan Penyelenggaraan Model Bilingual Faculty di FITK, IAIN Surakarta. Surakarta: LPPM IAIN Surakarta

Solikhah. 2014. Buku Teks Bahasa Inggris Akademik Berbasis Kompetensi Untuk Mahasiswa Jurusan Non-Bahasa Inggris (Penelitian dan Pengembangan di Universitas Negeri di Jawa Tengah dan DIY). Disertasi, Surakarta: Program Pascasarjana UNS.

Thornburry, Scoot. 2005. How to Teach Speaking. London: Pearson Education Limited. Yamashiro, D. Amy \& Johnson, Jeff. Public Speaking EFL: Elements for Course Design. The Language Teacher, 21(4):1-9. 